\title{
Amidine Derivatives and Leishmania amazonensis: an Evaluation of the Effect of Nitric Oxide (NO) Production on the Parasite-macrophage Interaction
}

R.M. Temporal, L. Cysne-Finkelstein, A. Echevarria, A.J. Silva-Gonçalves, L.L. Leon \& M.S. Genestra

To cite this article: R.M. Temporal, L. Cysne-Finkelstein, A. Echevarria, A.J. Silva-Gonçalves, L.L. Leon \& M.S. Genestra (2005) Amidine Derivatives and Leishmania amazonensis: an Evaluation of the Effect of Nitric Oxide (NO) Production on the Parasite-macrophage Interaction, Journal of Enzyme Inhibition and Medicinal Chemistry, 20:1, 13-18, DOI: 10.1080/14756360400015207

To link to this article: https://doi.org/10.1080/14756360400015207

Published online: 03 Oct 2008.

Submit your article to this journal $\pi$

Џll Article views: 50

Q View related articles $\sqsubset$

Citing articles: 10 View citing articles $\widetilde{\jmath}$ 


\title{
Amidine Derivatives and Leishmania amazonensis: an Evaluation of the Effect of Nitric Oxide (NO) Production on the Parasite-macrophage Interaction
}

\author{
R.M. TEMPORAL ${ }^{1}$, L. CYSNE-FINKELSTEIN ${ }^{1}$, A. ECHEVARRIA ${ }^{2}$, \\ A.J. SILVA-GONÇALVES ${ }^{3}$, L.L. LEON ${ }^{1}$, \& M.S. GENESTRA ${ }^{1}$ \\ ${ }^{1}$ Department of Immunology, Instituto Oswaldo Cruz/FIOCRUZ, Rio de faneiro, Brazil, ${ }^{2}$ Department of Chemistry, \\ Universidade Federal Rural do, Rio de Faneiro, Brazil, and ${ }^{3}$ Department of Biochemistry and Molecular Biology, Instituto \\ Oswaldo Cruz /FIOCRUZ, Rio de faneiro, Brazil
}

(Received 13 February 2004; In final form 15 fune 2004)

\begin{abstract}
Previous work has demonstrated that $N$ - $N^{\prime}$-diphenyl-R-benzamidine was highly effective against Leishmania amazonensis promastigotes/axenic amastigotes and Trypanosoma evansi trypomastigotes and the compound with a methoxy substituent, was the most effective derivative in the parasite-macrophage interaction. Comparative analysis of the nitric oxide (NO) released from the culture infection's supernatant showed the amidine to be less effective than pentamidine Isethionate as a reference drug. Additionally, in order to verify if the methoxylated derivative interferes with NO production by L. amazonensis, the effect of the amidine on the constitutive nitric oxide synthase (cNOS) purified from parasites, was examined, but demonstrated less activity in comparison with the reference drug. This data contributes to studies concerning the metabolic targets present in Leishmania parasites for leishmanicidal drugs.
\end{abstract}

Keywords: Leishmania amazonensis, nitric oxide, Nitric oxide synthase, pentamidine, methoxy-amidine

\section{Introduction}

Nitric oxide (NO) is a small radical biosynthesized from L-arginine by the enzyme nitric oxide synthase (NOS) in a two stage oxidation reaction that results in two products: L-citruline and NO, the latter with an extremely short life $[4,10]$. A NOS family exists in mammals, that includes a constitutive isoform (cNOS) expressed in certain neuronal (nNOS) and endothelial (eNOS) cells, in contrast with the inducible isoform (iNOS), expressed preferably in macrophages [33]. All the NOS enzymes so for characterized are hemoprotein dimers comprised of subunits and required cofactors such as NADPH, tetrahydrobiopterin $\left(\mathrm{H}_{4} \mathrm{~B}\right)$, FAD and FMN. All NOS isoforms are regulated by calmodulin, while nNOS and eNOS regulation depends on $\mathrm{Ca}^{2+}$ concentrations. $\mathrm{NO}$ is a labile molecule, and it may play important biological functions in the cell in which it is synthesized, and in its interaction with molecules within neighboring cells. The lipophilic properties of NO allows an easy diffusion through the membranes and on the cellular environment, but this radical can be stabilized or degraded by its interaction with diverse intra- and extracellular molecular residues [28].

Leishmania parasites are associated with a wide spectrum of clinical forms of the disease, from cutaneous infections to severe visceral or diffuse cutaneous leishmaniasis, turning into a major public health problem. The control of the disease in the New World is difficult due to the great variety of different species and its clinical manifestations. The drugs chosen for treatment of all clinical forms of leishmaniasis are sodium stibogluconate (Pentostam)

Correspondence: R. M. Temporal, Department of Immunology, Instituto Oswaldo Cruz/FIOCRUZ, Rio de Janeiro, Brazil. Fax: 5 21 2280 1589. E-mail: temporal@ioc.fiocruz.br 
and meglumine antimonate (Glucantime). Alternative drugs, such as pentamidine, amphotericin $\mathrm{B}$ and some azo-derivatives, are highly toxic, producing serious side effects. NO production appears to constitute one of the main microbiocidal mechanisms of the murine macrophage [27] and has been implicated in the elimination of several microorganisms, including Leishmania.

The mechanisms of action of NO on Leishmania are not well established, but it may act together with reactive oxygen species (ROS) in order to damage microbial DNA, proteins and lipids. NO can covalently react with intracellular iron, thus reacting with $\mathrm{Fe}-\mathrm{S}$ prosthetic groups of susceptible enzymes (e.g. aconitase, complex I and II of the mitochondrial electron transport chain) resulting in the formation of ironnitrosyl complexes with inactivation and degradation of these enzymes and cessation of replication. It has been confirmed by several laboratories that control of Leishmania infection in the murine model is NOdependent $[9,29]$.

Moreover, recently it has been reported that L. amazonensis also produces NO (detected as nitrite in the culture supernatant); it can be hypothesized that, depending of NO concentration, there exists a cross-talk or a down regulation mechanism involving parasites and host cells, favorable or not to the establishment of infection $[1,16-18]$. Inherently to these aspects, NO participation in other host-parasites interactions has been described [24,31] so that, the NO pathway of Leishmania parasites can constitute a good target for leishmanicidal drugs, without interference with NO production by the host cell. This work aims to show NO production during the host cell-parasite interaction and the interference of certain drugs against the defense systems of $L$. amazonensis.

\section{Materials and methods}

\section{Reagents}

Benzamidine, trypsin inhibitor, penicillin $\mathrm{G}, \mathrm{KCl}$, leupeptin, L-glutamine, Schneider's Insect Medium, $\mathrm{MgCl}_{2}$, phenylmethylsulfonyl fluoride (PMSF), $\mathrm{N}$-1-naphthylethylenediamine, phosphoric acid, sulfanilamide, sucrose, Tris $\mathrm{HCl}$, dithiotritol (DTT), aprotinin, L-arginine, NADH, NADP, NADPH, EDTA, (6R)-5,6, 7,8-tetrahidrobiopterin $\left(\mathrm{H}_{4} \mathrm{~B}\right), 2^{\prime}-5^{\prime}$ ADP agarose were from Sigma Chemical Co., St. Louis, MO (USA). Glycerol was from Bio Rad (USA). Fetal calf serum (FCS) was from Gibco BRL (USA). Amicon was obtained from Danvers, MA (USA).

\section{Parasites}

Leishmania amazonensis promastigotes (MHOM/BR/ $77 /$ LTB0016 strain) were grown at $26^{\circ} \mathrm{C}$ in Schneider's medium supplemented with $10 \%(\mathrm{v} / \mathrm{v})$ of fetal calf serum (FCS), $\mathrm{pH} 7.2$ at the late log phase of growth [11]. Parasites were harvested from the culture medium (with/without the drugs), counted in a Neubauer's chamber and adjusted to a concentration of $4 \times 10^{6}$ promastigotes $/ \mathrm{mL}$.

\section{Synthesis}

$\mathrm{N}, N^{\prime}$-diphenyl-4- $\mathrm{OCH}_{3}$-benzamidine was synthesized from the corresponding $4-\mathrm{OCH}_{3}$-benzanilide with phosphorus pentachloride $\left(\mathrm{PCl}_{5}\right)$, giving 4- $\mathrm{OCH}_{3}$-benzimidoyl chlorides in situ, followed by the addition of aniline to afford the target compounds. The amidine derivative in $80-90 \%$, yield was recrystallized from methanol/toluene and fully characterized by IR, ${ }^{1} \mathrm{H}$ and ${ }^{13} \mathrm{C}$ NMR and mass spectrometry [12].

\section{Drug assay}

For the "in vitro" assay, experiments were carried out in triplicate as follows: 1) Balb/c mice peritoneal macrophages were cultured in presence/absence of methoxy-amidine; 2) parasites (not treated/treated $24 \mathrm{~h}-26^{\circ} \mathrm{C}$ with the drugs) were added in a proportion of parasite:macrophage of $5: 1 ; 3$ ) drugs were added after infection was installed and 4) a control without parasite. The drug concentrations added in all assays corresponded to the $\mathrm{LDs}_{50}$ of the compounds. All tests were done using Pentamidine Isethionate (Figure 1) as the reference drug [34].

\section{Nitrite determination}

Macrophage culture supernatants were used to test $\mathrm{NO}$ production. Nitrite, a stable breakdown of NO, was measured spectrophotometrically by adding Griess reagent $(0.1 \% \mathrm{~N}-1$-naphthylethylenediamine in $5 \%$ phosphoric acid and $1 \%$ sulfanilamide) to the same volume of culture supernatant. After 10-15 min at room temperature, the absorbance of the mixture was measured at $540 \mathrm{~nm}$. Nitrite concentrations were estimated by comparison with a standard curve prepared with sodium nitrite [21].

\section{Purification of NOS from L. amazonensis promastigotes}

A cell-free extract was prepared from promastigotes (cultures containing $\sim 73 \%$ of metacyclic forms) by freeze-thawing the cell suspension $\left(5 \times 10^{9}\right.$ cells $\left.\mathrm{mL}^{-1}\right)$ 3-5 times and sonicating for $5 \times 45 \mathrm{~s}$ over ice in $0.25 \mathrm{~mol} / \mathrm{L}$ sucrose containing $5 \mathrm{mmol} / \mathrm{L} \mathrm{KCl}$. The contents were centrifuged at $10,000 \mathrm{~g}$ for $30 \mathrm{~min}$ and the supernatant was adjusted with antiproteolytic buffer containing: $0.1 \mathrm{mmol} / \mathrm{L}$ PMSF (phenylmethylsulfonyl fluoride), $0.01 \%$ (p/v) leupeptin, $0.2 \mathrm{mg} / \mathrm{mL}$ trypsin inhibitor and $1 \mathrm{mmol} / \mathrm{L}$ benzamidine to a final volume of $5 \mathrm{~mL}$. The crude soluble extract was centrifuged at $100,000 \mathrm{~g}$ for $60 \mathrm{~min}$ at $4^{\circ} \mathrm{C}$ and the supernatant $(1.01 \mathrm{mg} / \mathrm{mL}$ protein) was applied to a column 
(a)

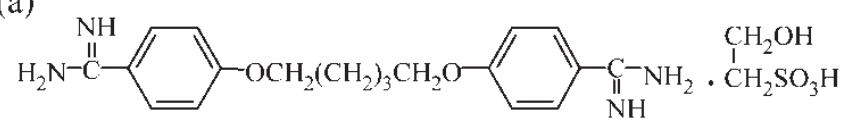

Pentamidine Isethionate

(b)

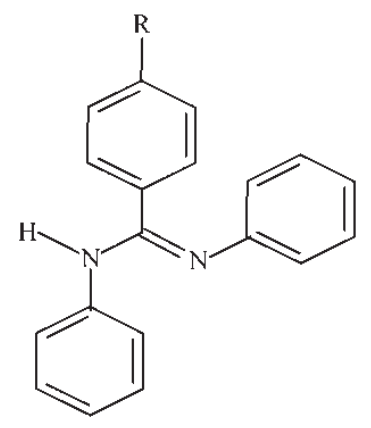

$\mathrm{N}, \mathrm{N}^{\prime}$-diphenyl-4-R-benzamidine

$\mathrm{R}=\mathrm{OCH}_{3}$

Figure 1. Chemical structure of Pentamidine Isethionate (a) and Methoxy-amidine (b).

$(8.5 \times 1.5 \mathrm{~cm})$ packet with $2^{\prime}, 5^{\prime}-$ ADP agarose equilibrated with $10 \mathrm{mmol} / \mathrm{L}$ Tris- $\mathrm{HCl}, \mathrm{pH} 7.5$ containing $1 \mathrm{mmol} / \mathrm{L}$ DTT (dithiotreitol), $1 \mathrm{mmol} / \mathrm{L}$ EDTA, $0.5 \mathrm{mmol} / \mathrm{L}$ PMSF, 25 units $/ \mathrm{ml}$ aprotinin and $0.5 \mathrm{mmol} / \mathrm{L}$ L-arginine (buffer A). The column was then washed successively with $20 \mathrm{~mL}$ of buffer A, $20 \mathrm{~mL}$ of buffer A containing $0.5 \mathrm{mmol} / \mathrm{L} \mathrm{NADH}$, $20 \mathrm{~mL}$ of buffer A contaning $0.5 \mathrm{mmol} / \mathrm{L}$ NADP and $20 \mathrm{~mL}$ of buffer A. The enzyme was eluted with $10 \mathrm{~mL}$ of buffer A containing $10 \mathrm{mmol} / \mathrm{L} \mathrm{NADPH}$, $3 \mu \mathrm{mol} / \mathrm{L} \mathrm{H}_{4} \mathrm{~B}$ and $10 \%(\mathrm{v} / \mathrm{v})$ glycerol and concentrated to $2 \mathrm{~mL}$ using an Amicon concentrator (Danvers, MA, USA). The protein concentration $(126 \mu \mathrm{g} / \mathrm{ml})$ was estimated spectrophotometrically $(260-280 \mathrm{~nm})$ and the samples were utilized to evaluate purity by SDS-PAGE $[3,8,15]$.

\section{Effect of amidine derivatives on NOS-promastigotes activity}

The activity of NOS (in presence/absence of drug) purified from Leishmania parasites was determined by measuring the decrease in the absorbance (JEWAY 6405 Spectrophotometer,U.K.) at $340 \mathrm{~nm}$ of $\mathrm{NADPH}$ consumed during the conversion of Larginine to L-citrulline by NOS. The complete enzyme reaction mixture contained $50 \mathrm{mmol} / \mathrm{L}$ potassium phosphate buffer ( $\mathrm{pH} 7.4$ ), $1 \mathrm{mmol} / \mathrm{L} \mathrm{CaCl}_{2}$, $0.1 \mathrm{mmol} / \mathrm{L} \quad \mathrm{NADPH}, 80 \mu \mathrm{mol} / \mathrm{L} \quad \mathrm{H}_{4} \mathrm{~B}, 10 \mu \mathrm{mol} / \mathrm{L}$ FAD, $10 \mu \mathrm{mol} / \mathrm{L}$ FMN $0.1 \mathrm{mmol} / \mathrm{L}$ L-arginine, $2 \mu \mathrm{g}$ enzyme, methoxy-amidine $\left(\mathrm{LD}_{50}=22 \mu \mathrm{mol} / \mathrm{L}\right)$ or pentamidine $\left(\mathrm{LD}_{50}=0.46 \mu \mathrm{mol} / \mathrm{L}\right)$ in a final volume of $2 \mathrm{~mL}$, at $25^{\circ} \mathrm{C}$. Blanks contained all the component's, except L-arginine and the amidine compounds $[8,22,32]$.

\section{Data analysis}

Three to five independent experiments were performed to quantify the levels of nitrite in supernatants cultures and determination of NOS activity. Data obtained with different treatments were analyzed statistically by 1 -way ANOVA and Students $t$-test $(\mathrm{p}<0.05)$.

\section{Results}

Previous data from the authors laboratory has shown that the most effective amidine derivative against L. amazonensis promastigotes and axenic amastigotes was that with a methoxy group as substituent. In this work the effect of the amidine derivative on NO production of the parasite-macrophage interaction ( $24 \mathrm{~h}$ post infection) was evaluated. NO production when parasites were pre-treated with methoxyamidine for $24 \mathrm{~h}$ before infection was higher (Figure 2a), compared with data observed when pentamidine was used $(\mathrm{p}=0.0194)$, but the percentage of infection was flagrantly lower when the parasites were pre-treated with the methoxy compound (Figure $2 \mathrm{~b}$ ). The results show that after the infection have been installed, the methoxy derivative was able to destroy the interiorized parasites, without being hazardous to the host cell (Figure 2b). Moreover, the methoxy derivative was also able to prevent macrophage infection with previously treated parasites (promastigotes incubated for $24 \mathrm{~h} / 26^{\circ} \mathrm{C}$ with the drug), even with a high production of nitrite (Figure 2a).

The presence of pentamidine did not have any effect in preventing infection under the same conditions 

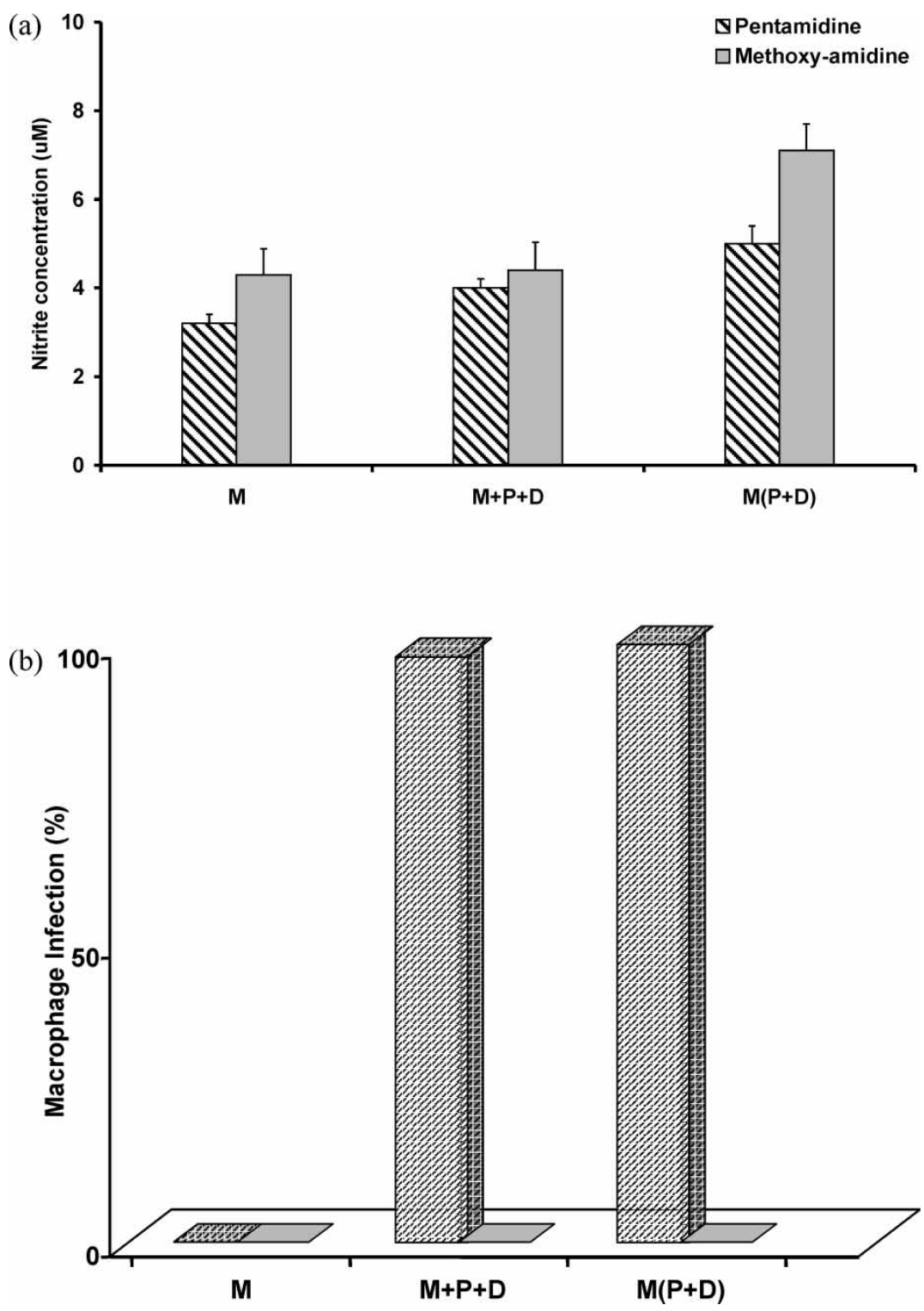

Figure 2. NO released ( $24 \mathrm{~h}$ post-infection) and (a) detected as nitrite in supernatant culture of L. amazonensis-macrophage interaction, (b) analyzed comparatively with percentage of infection. Where $\mathrm{M}=$ macrophage culture, $\mathrm{P}=$ parasites and $\mathrm{D}=$ drug. The protocol variables included: $M=$ only macrophage culture; $M+P+D=$ macrophage infected with $L$. amazonensis and then treated with the drug; $\mathrm{M}(\mathrm{P}+\mathrm{D})=$ L. amazonensis parasites were pre-treated with the drug for $24 \mathrm{~h}$ and then the macrophages were infected.

since the parasites treated with the reference drug, were able to promote macrophage infection (100\%) (Figure 2b).

Figure 3 showed that the methoxylated compound was able to inhibit significantly the purified NOS- $L$. amazonensis promastigotes activity $(\mathrm{p}=0.0293)$, demonstrated by a lower consumption of the NADPH in the conversion of L-arginine to L-citrulline.

\section{Discussion}

NO production appears to constitute one of the main microbiocidal mechanisms of murine macrophages and it has been implicated in the elimination of viruses, bacteria, fungi and protozoa [27]. Because of its variety of reaction partners (DNA, proteins, low-molecular weight thiols, prosthetic groups, reactive oxygen intermediates), its widespread production by three different NOS and the fact that its activity is strongly influenced by its concentration, NO continues to surprise and perplex immunologists, parasitologists and biochemists researchers [4].

Resistance to leishmanial infections depends on killing the intracellular parasite by activated host macrophages through the L-arginine-NO metabolic pathway [26]. Recently, Holzmuller et al. (2002) [23] have demonstrated that the exposure of amastigotes to moderate concentrations of NO-donating compounds (acidified sodium nitrite or nitrosylated albumin) or to endogenous NO produced by lipopolysaccharide or gamma interferon treatment of infected macrophages, resulted in a dramatic time-dependent cell death. 


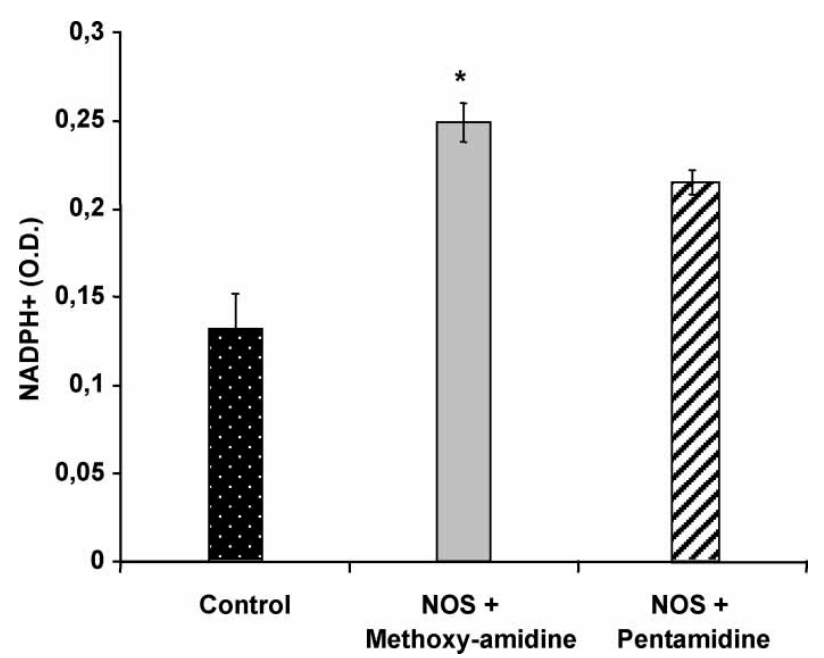

Figure 3. Activity of constitutive nitric oxide synthase (cNOS) of $L$ - amazonensis promastigotes analyzed by the consumption of NADPH. When the enzyme was incubated with the methoxy derivative $\left(\mathrm{LD}_{50}=14 \mu \mathrm{M}\right)$, the consumption of the cofactor was lower, in comparison with when the enzyme was incubated with pentamidine (reference drug, $\left.\left(\mathrm{LD}_{50}=0.46 \mu \mathrm{M}\right)\right)$. This data shows that the NOS-promastigotes activity of $L$. amazonensis is significantly ( $\mathrm{p}=0.0293)$ affected by methoxy-amidine.

While other parasites can also infect macrophages, Leishmania is distinctive in that not only does it rely on its own defenses to survive and reproduce within the macrophage phagolysosome, Leishmania also manipulates the host immune response in order to protect itself and to gain entry into the cell. These unique adaptive mechanisms help to promote survival of the Leishmania.

Studies performed on mice infected with L. major, have demonstrated that host defense against this infection depends on the interleukin-12-driven expansion (IL-12) of the $\mathrm{T}$ helper 1 cell subset, with production of cytokines, such as interferon-gamma, which activates the macrophages for killing the parasite through release of NO. The microbiocidal role of this radical is now emerging also in the human and canine model $[5,27]$.

In this work, it was possible to observe that $\mathrm{NO}$ production (detected as nitrite in culture supernatant) during the host cell-parasite interaction is directly proportional to percentage of infection. Moreover, the most important data observed is the absence of infection when parasites (treated/non-treated) were added to macrophages (without drugs) in comparison to pentamidine isethionate. Under the same conditions this observation was detected at $24 \mathrm{~h}$ post infection, and additionally demonstrates that methoxy-amidine did not interfere with NO production by macrophages, as observed in the control. Analysis of the results analysis have shown that methoxy-amidine acts on the defense systems of $L$. amazonensis, corroborating the data obtained by Genestra and collaborators [19]. At $24 \mathrm{~h}$, the higher detected nitrite level when the parasites were pre-incubated with methoxy-amidine can be due to intense parasite killing post interaction parasite-macrophage, maybe because the methoxy derivative interferes with the cross-talk of macrophage-parasites.

Previously, the authors analyzed the pathways signs in L. amazonensis promastigotes and the results showed a significant increase in PKG activity in the promastigotes culture containing a high percentage of metacyclic forms [13]. Therefore, the authors studied the existence of the $\mathrm{NO} /$ guanylate cyclase (GC)/cyclic guanosine monophosphate (GMP)/protein kinase G (PKG) pathway in these parasites, and they have associated the involvement of Leishmania-NOS enzyme systems in mechanisms of infectivity involving macrophages and also perhaps as a drug target. The data obtained corroborate the view that this pathway is present in L. amazonensis, the etiological agent of various forms of the Leishmaniasis. In past analysis of NO production by these parasites in supernatant culture, the results revealed a significantly higher $\mathrm{NO}_{2}^{-}$ (a byproduct of $\mathrm{NO}$ ) concentration in infective promastigotes, when compared with parasites with $n$ passage (non infective promastigotes, without metacyclic forms detectable) $[18,19]$.

In this work, a NOS was purified from the soluble extracts of $L$. amazonensis promastigotes forms. The purification protocol was similar to the employed for the purification of the L. donovani NOS-enzyme [3] and T. cruzi NOS-enzyme [30]. Previous results from the purification protocol have demonstrated that the representative silver-stained SDS gel shows that the purified preparation of $L$. amazonensis promastigotes NOS contained one single protein, which we believe to be a Leishmania NOS subunit $[15,18]$.

Among the several amidine derivatives [12] tested by the authors group on Leishmania amazonensis, they defined as the most effective compound that with a methoxy group as substituent [6,7] (Figure 1). The drug showed a high effectiveness against Trypanosoma evansi trypomastigotes, T. cruzi and PKA-L. amazonensis activity $[6,14,20]$. Following this data, the authors analyzed the effect of these compounds, in comparison with pentamidine (drug reference), on $\mathrm{NO}$ production by $L$. amazonensis promastigotes and axenic amastigotes by measuring nitrite, a by-product of NO released into the culture supernatants. The results indicated that $\mathrm{NO}$ production by infective promastigotes was significantly inhibited by methoxyamidine [17].

Amidine derivatives contains a chemical structure shared by the guanidine group of the NOS substrate L-arginine, suggesting the possibility of an interaction with this enzyme or electronic factors that will alter physical and chemical properties significant for NOS activity. Initially, the authors hypothesized that these drug can only inhibit the L-arginine transport of the Leishmania protozoan parasite [25]. Then, in order to verify the effect of methoxy-amidine on purified NOSL. amazonensis, they carried out an assay to analyze if 
whether there was a direct action of these compounds on NADPH consumption by this enzyme when the mixture reaction contained all the components involved in NO production. The results showed that the methoxylated compound was able to significantly inhibit the purified NOS-L. amazonensis activity ( $\mathrm{p}=$ 0.0293), demonstrated by the low consumption of $\mathrm{NADPH}$ on conversion of L-arginine to L-citrulline. This suggests that the methoxy-amidine interferes directly with NOS-Leishmania, through an unknown mechanism. Therefore, it seems that these mechanisms of action are involved in the reduction of macrophage infection observed "in vitro", corroborated by the fact that the methoxy-derivative is non toxic and does not interfere with the morphology of the host cell [34].

In general, the electronic factors ( $\sigma$ substituent), such as the inductive and the resonance effects are responsible for alterations in the physical and chemical properties of the compound, reflecting its biological activity. It is known that covalent bond formation between the drug and the target is not the only essential factor for a strict binding receptor-ligand; electrostatic interactions, hydrogen bonding and hydrophobic interactions can be equally important for the mechanism of action [2]. Based in the data presented here it is suggested that the NOS activity of $L$. amazonensis is a possible target for amidine compounds.

\section{References}

[1] Balestieri FM, Queiroz AR, Scavone C, Costa VM, BarralNetto M, Abrahamsohn A, Microbes Infect 2002;4(1):23-29.

[2] Barret MP, Fairlamb AH, Parasitol Res 1999;315:631-634.

[3] Basu NK, Kole L, Ghoshi A, Das PK, FEMS Microbiol Lett 1997;156:43-47.

[4] Bogdan C, Nat Immunol 2001;2(10):907-916.

[5] Brandonisio O, Panaro MA, Sisto M, Acquafredda A, Fumarola L, Leogrande D, Parassitologia 2000;42:183-190.

[6] Canto-Cavalheiro MM, Echevarria A, Araujo CA, Bravo MF, Santos LH, Jansen AM, Leon LL, Microbios 1997;90:51-60.

[7] Canto-Cavalheiro MM, Echevarria A, de Souza MA, CysneFinkelstein L, Torres MA, Leon LL, Arzneim-Forsch/Drug Res 2000;50:925-928.

[8] Chen Y, Rosazza JPN, Biochem Biophys Res Commun 1994;203:1251-1258.

[9] Clark IA, Rockett KA, Adv Parasitol 1996;37:1-56.
[10] Cunningham AC, Exp Mol Pathol 2002;72(2):132-141.

[11] Cysne-Finkelstein L, Aguiar-Alves F, Temporal RM, Leon LL, Exp Parasitol 1998;89:58-61.

[12] Echevarria A, Santos LH, Miller J, Mahmood N, Bioorg Med Chem Lett 1996;6:1901-1904.

[13] Fonseca-Geigel, L. A via do óxido nítrico em Leishmania amazonensis, MSc Thesis Brazil), Oswaldo Cruz Foundation 2000.

[14] Genestra M, Echevarria A, Cysne-Finkelstein L, Leon LL, Arznein-Forsch/Drug Res 2001;11:46-49.

[15] Genestra, M. Óxido nitrico sintase e proteína quinase A como alvos de derivados amidínicos anti-Leishmania, $\mathrm{PhD}$ Thesis Brazil), Oswaldo Cruz Foundation 2002.

[16] Genestra M, Cysne-Finkelstein L, Leon LL, Med Microbiol Immunol 2003a;192:217-223.

[17] Genestra M, Echevarria A, Cysne-Finkelstein L, VignólioAlves L, Leon LL, Nitric Oxide Biol Chem 2003b;8:1-6.

[18] Genestra M, Cysne-Finkelstein L, Guedes-Silva D, Leon LL, J Enz Inhib Med Chem 2003c;18:445-452.

[19] Genestra M, Souza WJS, Guedes-Silva D, Machado GMC, Cysne-Finkelstein L, Leon LL, Biol Res 2005; , submitted.

[20] Gomes-Cardoso L, Echevarria A, Aguiar-Alves F, CysneFinkelstein L, Canto-Carvalheiro MM, Genestra MS, Leon LL, Mem Inst Oswaldo Cruz 1998;93(suppl 1):312.

[21] Green LC, Wagner DA, Glogowski J, Skipper PL, Wishnok JS, Tannenbaum SR, Anal Biochem 1984;126:131-136.

[22] Hiki K, Hattori R, Kawai C, Yui Y, J Biochem 1992;111:556-558.

[23] Holzmuller P, Sereno D, Cavaleyra M, Mangot I, Daulouede S, Vincendeau P, Lemesre JL, Infect Immunol 2002;70(7): 3727-3735.

[24] Johanson KU, Carberg M, Adv Neuroimmunol 1995;5:431-442.

[25] Kandpal M, Fouce RB, Pal A, Guru PY, Tekwani NL, Mol Biochem Parasitol 1993;71:193-201.

[26] Laskay T, Diefenbach A, Röllinghoff M, Solbach W, Eur J Immunol 1995;25:2220-2227.

[27] Liew FY, Li Y, Moss D, Parkinson C, Rogers MV, Moncada S, Eur J Immunol 1991;21:3009-3014.

[28] Nathan C, Xie QW, Cell 1994;78:915-918.

[29] Oswald IP, Wynn TA, Sher A, James SL, Comp Biochem Physiol Pharmacol Toxicol Endocrinol 1994;108:11-18.

[30] Paveto C, Pereira C, Espinosa J, Montagna AE, Farber M, Esteva M, Flawia MM, Torres HN, J Biol Chem 1995;270:1-4.

[31] Schmidt HH, Gagne GD, Nakane M, Pollock JS, Miller MF, Murad F, J Histochem Cytochem 1992;40:1439-1456.

[32] Sherman PA, Laubach VE, Reep BR, Wood ER, Biochemistry 1993;32:11600-11605.

[33] Stuher DJ, Biochem Biophys Acta 1999;1411:217-230.

[34] Temporal RM, Cysne-Finkelstein L, Echevarria A, de Souza MA, Sertã M, Silva-Goncalves AJ, Pirmez C, Leon LL, Arznein-Forsch/Drug Res 2002;52:489-493. 